\title{
Modulation of Melanotransferrin and Transferrin Receptor 1 (TFRC)- and CD44-based Signaling for TFRC Up-regulation in Human Melanoma Cells
}

\author{
FRIEDEMANN LAUBE and DAGOBERT GLANZ
}

Martin Luther University Halle-Wittenberg, Institute of Physiological Chemistry, Halle, Germany

\begin{abstract}
Background: The human melanoma cell line IGR1 was used for the detection and regulation of both melanotransferrin (MTf) and transferrin receptor 1 (TFRC, CD71). While the function in iron transport of the TFRC is well documented the functional importance of MTf is not yet fully understood. Due to the up-regulation of TFRC by hyaluronan (HA) some components and aspects of CD44 signaling were investigated. Materials and Methods: The cell-surface proteins MTf, TFRC and ERBB2 receptor tyrosine kinase 2 (ERBB2) were detected by immunoluminescent technique using different polyclonal and monoclonal antibodies. Ionomycin was used to inhibit $\beta$-catenin/T-cell-specific transcription factor (TCF) association, essential in HA-CD44-ERBB2 signaling. Results: MTf, was found to be resistant to phosphatidylinositol-specific phospholipase C. However, MTf as well as TFRC were sensitive to partial proteolytic degradation by pronase $E$ and trypsin. The expression of MTf was shown to be up-regulated by mannose-6-phosphate and that of TFRC by HA. Ionomycin at $10 \mu \mathrm{M}$ inhibited TFRC up-regulation. However, at $50 \mu \mathrm{M}$ it induced a 7.5-fold increase of TFRC concentration. Conclusion: Our results suggest that human melanoma cells are able to up-regulate TFRC expression using HA/CD44 signaling. The whole pathway comprises of the sequence: $H A / C D 44$, neural Wiskott-Aldrich syndrome protein ( $N$-WASP), ERBB2, $\beta$-catenin/TCF, $c$-MYC and TFRC. Since $\beta$-catenin is also known to be a component of wingless/Int-1-Frizzled signaling that also leads to transcriptional c-MYC activation, the pathway found here might be alternatively used by melanoma cells for iron supply, necessary for cell proliferation. Melanotransferrin (MTf) is highly expressed on melanoma
\end{abstract}

Correspondence to: Dr. Friedemann Laube, Institute of Physiological Chemistry, Martin Luther University Halle-Wittenberg, Hollystr. 1, 06097 Halle, Germany. Tel: +49 3455573822, e-mail: friedemann.laube@medizin.uni-halle.de

Key Words: Melanotransferrin (MTf), transferrin receptor 1 (TFRC), HA/CD44 signalling, human melanoma cells, immunoluminescence. cells compared to normal melanocytes (1). This so-called human melanoma-associated antigen p97 is bound to the plasma membrane via a glycosylphosphatidylinositol (GPI) anchor (2). The MTf molecule can bind iron through a single high-affinity iron-(III)-binding site. Despite its high sequence homology of $37-39 \%$ with human serum transferrin (Tf), soluble MTf (sMTf) cannot be bound by the transferrin receptor 1 (TFRC) nor by transferrin receptor 2. Further investigations have shown that MTf does not play a significant role in iron uptake by melanoma cells. However, MTf was found to function as a plasminogen binding site on the cell surface and enhances the activation of plasmin by plasminogen activator (3) e.g. urokinase plasminogen activator (4). This may result in fibrinolysis, matrix degradation and endothelial cell detachment. These processes may contribute to tumour cell invasion, angiogenesis and metastasis. Important functions of MTf in melanoma cell proliferation and tumorigenesis are described on the basis of MTf-knockout $\left(\mathrm{MTf}^{--}\right)$mice and post-transcriptional genesilencing experiments (5). A detailed review of MTf was recently published by Paluncic et al. (6).

TFRC is a type II transmembrane glycoprotein that is found on all nucleated cells (7). Commonly, the receptor forms disulfide-linked homodimers. Many malignant cell lines show increased expression of TFRC compared to cells of benign lesions or differentiated cell lines. The prominent function of TFRC is iron uptake by binding $\mathrm{Fe}^{3+}$-loaded transferrin and subsequent endocytosis. Thus, this ligand-receptor interaction ensures iron acquisition for energy metabolism (e.g. cytochromes and $\mathrm{Fe}-\mathrm{S}$ proteins in the respiratory chain) and especially for highly proliferating cells that need the essential ribonucleotide reductase as a Fe-dependent enzyme for DNA synthesis. Therefore, high expression of TFRC may constitute a typical biomarker of tumour cells.

This approach describes different agents capable of upregulating MTf and TFRC. Differences in regulation between these two proteins should be determined in order to find potential treatments leading to tumour repression. Additionally, the presence of CD44 on IGR-1 melanoma cells (4) and our 
observation that these cells up-regulate TFRC upon exposure to hyaluronan (HA) led to the signalling experiments described here. Our question was which signalling components are involved between the known CD44/HA interaction and the subsequent transactivation of TFRC. Bourguignon et al. proposed a model for ovarian tumour cells in which HA signals through a complex of CD44, neural Wiskott-Aldrich syndrome protein (N-WASP) and ERBB2 leading to the activation of a $\beta$-catenin-T-cell-specific transcription factor/lymphoid enhancer-binding factor (TCF/LEF) complex (8). On the other hand, it is known that $\beta$-catenin is also activated by the wingless/Int-1 (WNT)/Frizzled pathway leading to gene expression of c-MYC transcription factor $(9,10)$. Based on these findings we suggest that c-MYC may also function as a link in HA/CD44 signalling in melanoma cells. Since c-MYC controls TFRC gene expression (11) TFRC up-regulation by $\mathrm{HA}$ in the experiments described here is probably regulated by CD44. In order to demonstrate that $\beta$-catenin is involved in this pathway, ionomycin was used to inhibit the formation of a transcriptionally active $\beta$-catenin-TCF/LEF complex. The downregulation of $\beta$-catenin/TCF signalling by ionomycin in colon cancer cells was shown by Park et al. (12). Interestingly, ionomycin is described to be a $\mathrm{Ca}^{2+}$ ionophore (13) with the consequence that protein kinase $\mathrm{C}$ (PKC) can be activated by $\mathrm{Ca}^{2+}$ released from intracellular stores. Thus, ionomycin has different cellular effects dependent on its concentration as demonstrated here. This approach provides some insights into the complex interplay of different cell surface receptors (e.g. CD44, ERBB2 and TFRC) and describes an alternative pathway for the up-regulation of TFRC by HA-CD44-activated $\beta$-catenin independent of $\mathrm{WNT} / \beta$-catenin signaling. Components implicated in this network may represent possible targets for the tumour suppression.

\section{Materials and Methods}

Antibodies. Primary antibodies: rabbit anti-MTf (H-70. sc-25832), goat anti-MTf (P-20. sc-26649), goat anti-MTf (C-20. sc-26651), mouse monoclonal antibodies to human TFRC/CD71 (clone 3B8 2A1, $\mathrm{IgG}_{1}$ ), human ERBB2 (9G6, sc-08) and rabbit anti-ERBB2 (H200. sc-134481) were purchased from Santa Cruz Biotechnology, Heidelberg, Germany; mouse monoclonal antibody to human TFRC (clone DF 1513, $\operatorname{IgG}_{1}$ ) was from Sigma-Aldrich, Taufkirchen, Germany. Isotype controls and blocking antibodies: Mouse $\mathrm{IgG}_{1}$ (MOPC21), Sigma-Aldrich; ChromPure goat IgG, Dianova, Hamburg; normal rabbit IgG (sc-3888) was from Santa Cruz Biotechnology. Conjugates: horseradish peroxidase (HRP)conjugated $\left.\mathrm{F}(\mathrm{ab})_{2}\right)_{2}$ fragment goat anti-rabbit IgG $(\mathrm{H}+\mathrm{L})$, HRPconjugated $\mathrm{F}(\mathrm{ab})_{2}$ fragment goat anti-mouse IgG $(\mathrm{H}+\mathrm{L})$, HRPconjugated $\left.\mathrm{F}(\mathrm{ab})_{2}\right)_{2}$ fragment donkey anti-goat $\mathrm{IgG}(\mathrm{H}+\mathrm{L})$ were from Dianova, Hamburg, Germany.

Reagents. Phosphatidylinositol-specific phospholipase C (PI-PLC), (P5542), HA (H5388), trypsin (1:250, porcine pancreas), protease (pronase E, Streptomyces griseus) and 4-iodophenol were purchased from Sigma-Aldrich; recombinant human insulin-like growth factorII (rhIGF-II) was from ImmunoTools, Friesoythe, Germany; ionomycin was purchased from Biozol, Eching, Germany; Fura Red and Fluo-3 were purchased from Invitrogen, Darmstadt, Germany.

Cell line. The human melanoma cell line IGR-1 was kindly provided by Professor J. Wohlrab (Halle, Germany) and originally produced by Aubert et al. (14). The cell line was cultured as described previously (4). Briefly, cells were cultured in Dulbecco's modified Eagle's medium (DMEM) supplemented with Lglutamine, D-glucose, sodium pyruvate (Fisher Scientific, Schwerte, Germany) and $10 \%$ fetal calf serum (FCS), and contained penicillin, streptomycin and amphotericin B (Fisher Scientific). The cells were maintained at $37^{\circ} \mathrm{C}$ in a $10 \% \mathrm{CO}_{2}$ atmosphere.

Cell preparation. Cells were grown to near confluence, harvested with Accutase (PAA Laboratories, Pasching, Austria) according to the manufacturer's instructions and washed with phosphate-buffered saline (PBS; $10 \mathrm{mmol} / \mathrm{l}$ phosphate, $150 \mathrm{mmol} / \mathrm{l} \mathrm{NaCl}, \mathrm{pH}$ 7.4). To reconstitute cell surface proteins, cells were re-suspended and maintained in DMEM for $40 \mathrm{~min}$ at $37^{\circ} \mathrm{C}$.

Principles of experimental procedure. All experiments were performed three times to confirm the reproducibility of results. Within an experiment, each sample (aliquot: $10 \times 10^{6} \mathrm{cells} / \mathrm{ml}$ ) was measured four times with the luminescent test either after effector treatment following antibody labelling or after antibody labelling only.

Cell treatment with effectors. After preparation, cells were washed twice with PBS and divided into equal aliquots (each aliquot: $10 \times 10^{6}$ cells $/ \mathrm{ml}$ ) for incubation with different effectors: Mannose6-phosphate (M6P): 0, 5 and $10 \mathrm{mM}$ in PBS (pH 7.4) at $22^{\circ} \mathrm{C}$ and $37^{\circ} \mathrm{C}$ for $45 \mathrm{~min}$; HA: $0,192.3,384.6$ and $1,153.8 \mu \mathrm{g} / \mathrm{ml}$ in PBS $(\mathrm{pH} 7.4)$ at $37^{\circ} \mathrm{C}$ for $60 \mathrm{~min}$; ionomycin $(10 \mu \mathrm{M})$ as control; and $10 \mu \mathrm{M}$ ionomycin in addition to HA $(1153.8 \mu \mathrm{g} / \mathrm{ml}$ cell suspension $)$ to test the inhibition of HA/CD44 signalling by ionomycin; rhIGFII: $10^{-6} \mathrm{M}$ in PBS (pH 7.4) at $37^{\circ} \mathrm{C}$ for $45 \mathrm{~min}$. After incubation, cells of each sample were washed twice with PBS and subjected to cell labelling with appropriate antibody and conjugate. Finally, each sample was subjected to the luminescent test.

Cell labelling. Cells from each sample $\left(10 \times 10^{6}\right.$ cells $/ \mathrm{ml}$ PBS $)$ were incubated with appropriate antibody $\left(10 \mu \mathrm{g} / \mathrm{ml}, 60 \mathrm{~min}, 4^{\circ} \mathrm{C}\right.$, with gentle shaking) followed by washing the cells twice. Cells were then incubated with the corresponding conjugate $(1.5 \mu \mathrm{g} / \mathrm{ml}, 45 \mathrm{~min}$, $4^{\circ} \mathrm{C}$, with gentle shaking) and after washing twice, the cells were subjected to the luminescent test. Controls were measured under the same conditions as described for cell labelling of samples; for isotype controls normal mouse, rabbit and goat $\mathrm{IgG}(10 \mu \mathrm{g} / \mathrm{ml})$ was used instead of the corresponding specific antibody; conjugate controls were measured omitting the antigen-specific antibody.

Luminescence. Aliquots of each sample ( $25 \mu 1,2.5 \times 10^{5}$ cells $)$ were mixed with $250 \mu \mathrm{l}$ of the substrate solution $[10 \mathrm{mmol} / \mathrm{l}$ phosphate buffer, pH 7.4, luminol $/ \mathrm{H}_{2} \mathrm{O}_{2} / 4$-iodophenol (15)] and the light emission was measured as intensity (relative light units: RLU) for 60 s (single kinetics protocol, FB12 - PC Software; Berthold Detection Systems, Pforzheim, Germany). Signal registration over $60 \mathrm{~s}$ allows consideration of the individual kinetics of each sample for quantification. Each sample was measured four times. 
Melanoma cell incubation with trypsin and pronase E. Because the detachment of MTf from the cell surface was not successful, partial degradation with trypsin and pronase E was performed. TFRC was included in this attempt to compare the effects of both proteolytic enzymes with another cell surface protein. To $500 \mu \mathrm{l}$ cell suspension ( $10^{7}$ cells), $5 \mu \mathrm{l}$ of $0.1 \%$ trypsin and $2.5 \mu \mathrm{l}$ of $0.1 \%$ pronase E in PBS (pH 7.4), respectively, were added. The optimal concentrations for trypsin and pronase $\mathrm{E}$ were tested before (by microscopy and cell viability test). After $5 \mathrm{~min}$ incubation at room temperature, reactions were stopped: trypsin was stopped by phenylmethylsulfonyl fluoride (PMSF) alone (10 $\mu \mathrm{l}, 10 \mathrm{mM}$ in dimethyl sulfoxide) and pronase $\mathrm{E}$ by PMSF $(10 \mu \mathrm{l})$ as well as EDTA $(10 \mu \mathrm{l}, 1 \mathrm{mM}$ in PBS). After centrifugation and washing twice with ice-cold PBS, cells were subjected to cell labelling with antibodies and subsequently to luminescent measurement.

Statistical analysis. Statistical analyses were performed according to an unpaired one-sample Student $t$-test. Error bars show standard deviations calculated from the means $(n=4)$.

\section{Results}

Melanotransferrin was detected in the human melanoma cell line IGR-1 using three different antibodies (Figure 1). H-70 is a rabbit polyclonal antibody raised against amino acids 601670 mapping near the $C$-terminus of human MTf. This antibody preparation detects epitopes in a domain located 40 amino acids above the GPI anchor. Obviously, the protein structure representing the peptide sequence 601-670 produces epitopes with the best accessibility for this polyclonal antibody. Unlike this rabbit antibody, the goat polyclonal antibodies C-20 and P-20 were produced using shorter peptides ( $c$ a. 20 amino acids) for the immunization (C-20: peptide inside the sequence used for $\mathrm{H}-70$; P-20: peptide located in the $N$-terminal domain). Thus, both goat polyclonal antibodies gave signal intensities lower than that generated with H-70. The non-specific binding detected with appropriate normal rabbit or goat IgG was 5-6.5\% and the non-specific binding of the corresponding conjugate controls was $4-5 \%$.

The cleavage of GPI anchor and subsequent release of the protein in a soluble form is the most common criterion used in GPI anchor identification. Despite repeated experiments using PI-PLC under different conditions, the detachment of MTf was not successful. Therefore, the use of three different antibodies for the reliable detection of MTf was very important. Possible reasons for the PI-PLC-insensitive GPIprotein anchor are discussed below. Because of the failure of PI-PLC treatment, we chose protease digestion as an alternative method. Figure 2 shows the results from the treatment of melanoma cells with trypsin and pronase E, respectively. PMSF and EDTA were used as protease inhibitors to stop the reactions and to prevent cell damage. Both MTf and TFRC concentrations were significantly reduced due to partial proteolytic degradation. Trypsin caused a reduction of $53 \%$ and pronase $\mathrm{E}$ of $65.3 \%$ in MTf

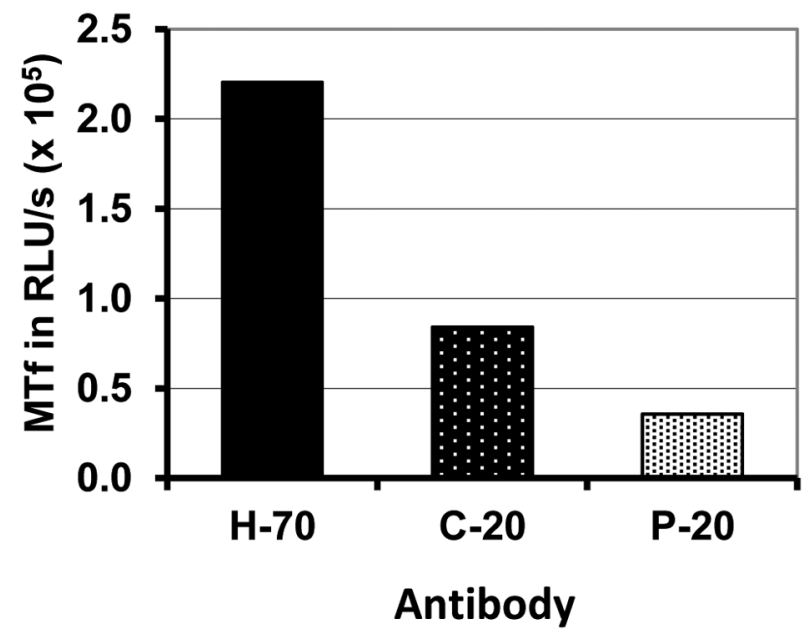

Figure 1. Three different antibodies were used for the detection of melanotransferrin (MTf) on IGR-1 cells. H-70: Rabbit polyclonal antibody $(p A b)$ detecting a peptide region near the $C$-terminus (amino acids 601-670); C-20: Goat pAb detecting epitopes of a C-terminal peptide; and P-20: Goat pAb detecting epitopes of an $N$-terminal sequence of human MTf.

immunoluminescence. The TFRC decline induced by trypsin and pronase $\mathrm{E}$ was $36 \%$ and $46 \%$, respectively. As shown by statistical analysis, the corresponding treatments with trypsin and pronase $\mathrm{E}$ gave significant differences compared to the controls (MTf and TFRC, respectively), whereas the inhibitor controls exhibited no significant reduction compared to $100 \%$ signal intensity for MTf and TFRC, respectively.

Previously it was shown that M6P stimulated the upregulation of IGF-II receptor (16) as well as alkaline phosphatase (17). Based on these results we have tested the effect of M6P on the MTf expression. Figure 3 demonstrates the increase of cell-surface MTf by cell incubation with M6P. Different temperatures used gave only a negligible difference in M6P-induced MTf expression. It was expected that a more physiological temperature would elicit a stronger regulatory effect. The maximal effect of M6P on melanoma cells was found to be at $5 \mathrm{mM}$ M6P. Results suggest that a stimulation of MTf synthesis occurred via M6P/IGF-II receptor interaction following signal transduction events. Previous data for the upregulation of different proteins by M6P allow the conclusion that this ligand affects the transcription of different genes via IGF-II receptor signalling. Besides the ligand M6P reacting with the M6P/IGF-II receptor, the mitogenic peptide IGF-II was used to test its effect on the MTf and TFRC expression. Melanoma cell incubation with rhIGF-II $\left(10^{-6} \mathrm{M}\right)$ did not affect the cell-surface expression of MTf or TFRC (data not shown). However, control experiments showed that rhIGF-II $\left(10^{-6} \mathrm{M}\right)$ as well as M6P (5 mM) up-regulated expression of M6P/IGF-II receptor (data not shown). 


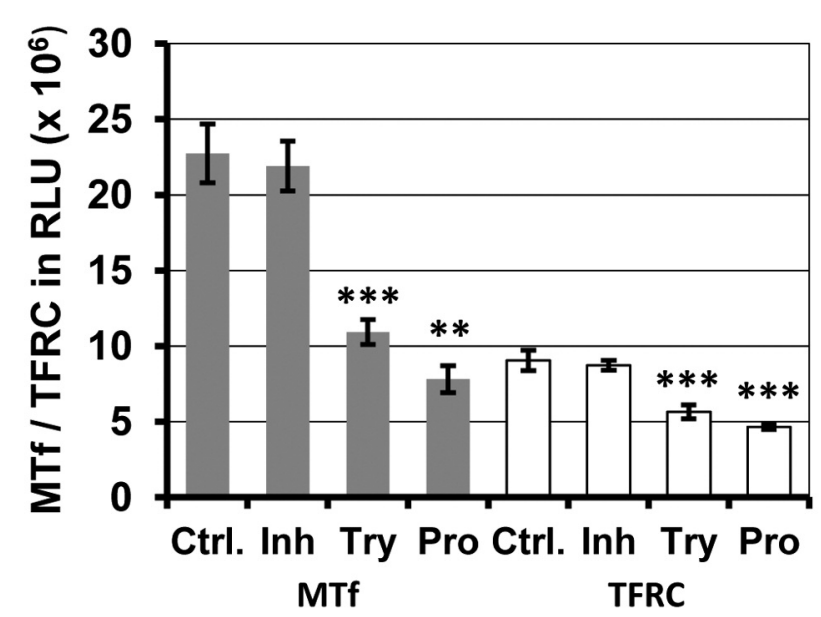

Figure 2. Partial proteolytic degradation of melanotransferrin (MTf) and transferrin receptor 1 (TFRC) by trypsin (Try) and pronase E (Pro) on IGR-1 cells. For experimental details see Materials and Methods. Both inhibition controls (Inh) show that inhibitors virtually do not impair the reduction of signals after partial proteolytic degradation of MTf and TFRC. Controls (Ctrl.): cells were incubated in PBS ( $p H$ 7.4) without Try and Pro. Experimental conditions used for Try and Pro caused a significant decline of MTf as well as TFRC concentration on IGR-1 cells compared with the corresponding Ctrl. $\left({ }^{* *} p \leq 0.01\right.$ and $\left.{ }^{* * *} p \leq 0.001\right)$.

Both antibodies used for the detection of TFRC showed

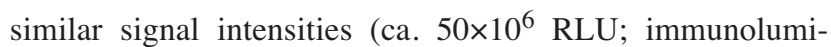
nescent detection, see also Figures 4 and 5). In order to test the TFRC regulation, it was hypothesized that CD44 binding to HA as its main ligand would lead to changes in TFRC concentration. Figure 4 shows the up-regulation of TFRC following incubation of melanoma cells with increasing HA concentration. The highest HA concentration used (1153.8 $\mu \mathrm{g} / \mathrm{ml}$ cell suspension) caused an increase of about $45 \%$ in the signal intensity compared to the control (cells incubated with PBS). Increasing HA concentration caused a significant increase of TFRC expression. Additional experiments showed that HA had no effect on MTf regulation.

To confirm that ERBB2 is involved in the signal transduction triggered by HA-CD44 interaction in IGR-1 melanoma cells, we detected the receptor tyrosine kinase ERBB2 using two antibodies: luminescent signal intensity with mouse mAb (9G6) was $20 \times 10^{6}$ RLU and that with rabbit pAb (H-200) $60 \times 10^{6} \mathrm{RLU}$ (results not shown). More widespread and up-regulated ERBB2 expression was described to be found in melanomas particularly in the vertical growth phase. Higher ERBB2 expression was also found in several melanoma cell lines (18). The participation of $\beta$-catenin in the signal transfer to TCF/LEF was shown by use of $10 \mu \mathrm{M}$ ionomycin (Figure 5). The strength of the TFRC increase stimulated by HA was completely reduced in the presence of IM. The control experiment with $10 \mu \mathrm{M}$

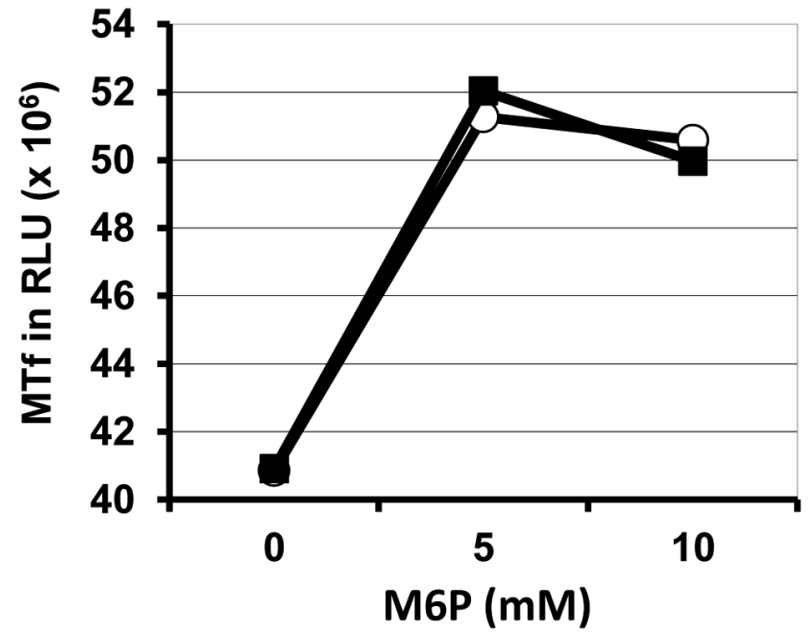

Figure 3. Mannose-6-phosphate (M6P) increased the melanotransferrin (MTf) expression on human melanoma cells IGR-1. Maximal effect was found at $5 \mathrm{mM} \mathrm{M6P,} \mathrm{(45} \mathrm{min} \mathrm{incubation,} \mathrm{PBS,} \mathrm{pH} \mathrm{7.4).} \mathrm{There} \mathrm{were} \mathrm{no}$ significant differences between values recorded at $22^{\circ} \mathrm{C}$ (open symbols) and $37^{\circ} \mathrm{C}$ (closed symbols).

ionomycin alone showed only a weak but significant increase $(p \leq 0.05)$ in TFRC expression. In contrast to the inhibitory effect of $10 \mu \mathrm{M}$ IM, $50 \mu \mathrm{M}$ ionomycin caused a 7.5-fold increase in TFRC expression (not shown). Additionally, the different effects of $10 \mu \mathrm{M}$ and $50 \mu \mathrm{M}$ ionomycin on the intracellular $\mathrm{Ca}^{2+}$ concentration was measured by confocal laser scanning microscopy using $\mathrm{Ca}^{2+}$-sensitive fluorescent dyes (Fura Red, Fluo-3; excitation: Ar laser $488 \mathrm{~nm}$ ). Ionomycin at $10 \mu \mathrm{M}$ induced a very low and short $\mathrm{Ca}^{2+}$ increase in melanoma cells, but $50 \mu \mathrm{M}$ ionomycin caused a high and more sustained increase in $\mathrm{Ca}^{2+}$ level (results not shown).

\section{Discussion}

Melanoma cells were used to detect MTf and TFRC and to modulate the cell-surface expression of these molecules. Both proteins contribute to the functional behaviour of malignant melanoma cells and are discussed as possible target molecules for antitumor treatment (19-21). Because of the failure of MTf detachment from cells by PI-specific PLC, MTf was identified using three different antibodies (Figure 1). Additionally, MTf as well as TFRC were investigated by their proteolytic susceptibility to trypsin and pronase E. It was shown that the immunoluminescent signals of both cellsurface proteins were clearly reduced by limited proteolysis (Figure 2). 


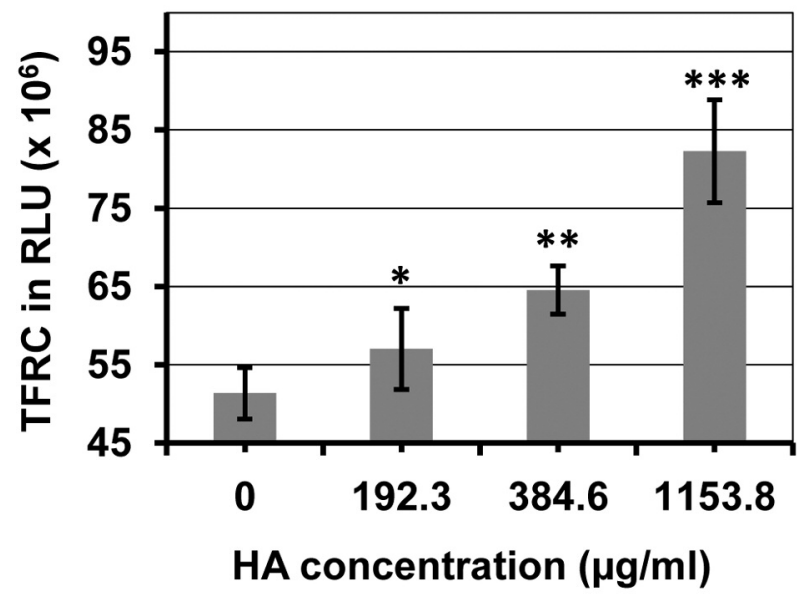

Figure 4. Incubation of human melanoma cells IGR-1 with increasing hyaluronan (HA) concentration results in up-regulation of the transferrin receptor 1 (TFRC) but not of melanotransferrin (MTf), (cells suspended in PBS, $p H 7.4 ; 1 \mathrm{~h}, 37^{\circ} \mathrm{C}$ ). Increasing $H A$ concentration caused elevation of TFRC expression with increasingly significant values compared with cells treated without $H A(* p \leq 0.05, * * p \leq 0.01, * * * p \leq 0.001)$.

The processing of the full-length MTf by a transamidase and the exploration of the $\omega$ position (Ser-710) for the GPI attachment is described by Yang et al. (22). After detachment of the hydrophobic $C$-terminal peptide (aa-711 - aa-738) the Ser-710 provides the $\mathrm{COOH}$ group to bind the GPI anchor. The GPI anchor of a protein may be resistant to degradation by PI-PLC for a variety of reasons (e.g. chemical modification, inaccessibility to PI-PLC, etc.). Besides the inaccessibility of the PI-PLC cleavage site due to the chemical nature of the lipid environment (glycocalyx, caveolae), acylation of the inositol ring involved in anchorage of the hydrophobic acyl residue with the plasma membrane might also explain the observed resistance. On the other hand, protease digestion experiments are described for the successful fragmentation of cell bound MTf in melanoma cells (23).

More important results regarding the role of MTf in melanoma cells were presented by Richardson et al. $(5,24)$. They demonstrated that MTf does not play an essential role in iron metabolism or homeostasis and identified differentially expressed genes (e.g. myocyte enhancer factor 2a (Mef2a), transcription factor $4(T c f 4)$, glutaminase $(G l s)$ and ATP-binding cassette subfamily B member 5 (Abcb5) which are involved in MTf down- or up-regulation. Thus, these genes may indirectly influence proliferation, cell migration and survival of melanoma cells. In contrast to TFRC, MTf is not regulated by cellular iron status and is not up-regulated in rapidly dividing cells. Considering these results and those described here, one can conclude that MTf and TFRC are differently regulated proteins and can be

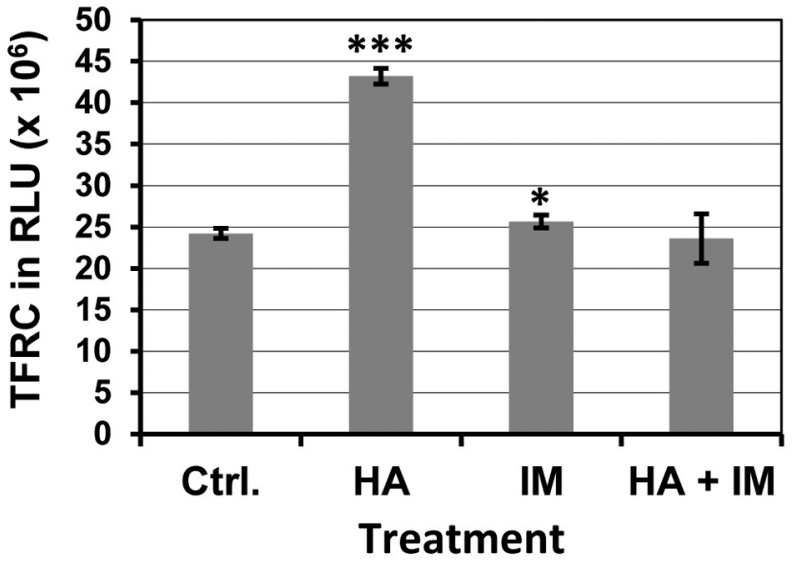

Figure 5. Induction of transferrin receptor 1 (TFRC) up-regulation by hyaluronan (HA) and its inhibition by ionomycin $(I M, 10 \mu M)$ in human melanoma cells. As a control (Ctrl.) cells were treated in phosphate

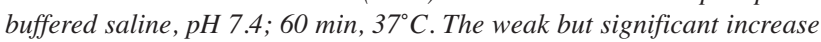
on treatment with IM compared with general Ctrl. reveals the beginning of $\mathrm{Ca}^{2+}$ release at $10 \mu \mathrm{M}$ IM and the moderate stimulation of TFRC expression probably by protein kinase $C$ signaling. Cells incubated with HA (1153.8 $\mu \mathrm{g} / \mathrm{ml}$ cell suspension) showed a significant increase of about $45 \%$ in TFRC that was completely reduced in the presence of 10 $\mu M$ IM (without significant difference compared with Ctrl.). Significantly different at $* p \leq 0.05$ and $* * * p \leq 0.001$.

modulated by specific molecules or specific signalling pathways. Here it was shown that MTf may be up-regulated by M6P, probably through the M6P/IGF-II receptor recently identified on IGR-1 melanoma cells (16). In contrast to TFRC, MTf was not up-regulated by HA. This suggests that MTf is not a target gene of c-MYC triggered by transcriptional activation of $\beta$-catenin following HA-CD44 interaction. Additionally, the mitogenic peptide hormone IGF-II (rhIGF-II) failed to up-regulate MTf and TFRC. Based on previous results on CD44 expression on IGR-1 melanoma cells, this approach aimed to demonstrate a possible link between HA-CD44 interaction and TFRC upregulation. TFRC function is required to provide the tumour cell with iron that is essential for DNA synthesis, cell metabolism and in the respiratory chain. Thus, it represents a key regulator of proliferation. It has been shown that there is a correlation between the cell-surface concentration of TFRC and the rate of cell proliferation. CD44 was found to mediate HA-binding and HA-induced cell proliferation in melanoma cells (25). It was reported that CD44-HA signalling through ERBB2 and $\beta$-catenin leads to transcriptional activation and cancer progression in ovarian tumour cells (8). Moreover, it was shown in colon carcinoma cells that $\beta$-catenin-LEF/TCF-induced transcriptional activation may up-regulate the transcription factor c-MYC $(9,10)$ based on WNT/ $\beta$-catenin signalling. However, up- 
regulation of TFRC upon CD44-HA interaction in human melanoma cells independent of WNT/ $\beta$-catenin signalling has not been described.

It is well documented that HA induces melanoma cell proliferation via membrane-bound CD44 (25). Moreover, blocking HA-CD44 interaction prevents malignant melanoma cell proliferation. On the other hand, TFRC is involved in the proliferation of tumour and non-tumour cells and little is known about the regulation of TFRC expression in melanoma. Here, it was shown that incubation of melanoma cells with elevated HA concentrations increased cell-surface expression of TFRC (Figure 4). This finding may link the signal transduction of HA-CD44 with TFRC up-regulation according to the sequence: HA - CD44 - N-WASP - ERBB2 - $\beta$ catenin/TCF - c-MYC - TFRC. Expression analysis of WNT target genes (26) in murine mammary epithelial cells exhibited elevated levels of $\beta$-catenin protein and of the genes $c-M Y C$ (by 62\%) and TFRC (by 70\%), $1 \mathrm{~h}$ after activation with WNT$3 \mathrm{~A}$. Thus, compared with these results, the chronological course for HA stimulation of melanoma cells described here $\left(1 \mathrm{~h}, 37^{\circ} \mathrm{C}\right)$ enables detection of changes in TFRC at the protein level, although $T F R C$ is an indirect target gene of transcriptional activation of $\beta$-catenin. Obviously, the results reveal an alternative signal transduction pathway compared to the WNT/ $\beta$-catenin pathway described for melanocytes and melanoma cells (27).

The oncogenic transcription factor c-MYC stimulates proliferation and growth by activating thousands of target genes. It was demonstrated that TFRC is a critical downstream target of c-MYC (28). However, the mechanism by which TFRC expression is increased in neoplastic cells remained poorly characterized (28). Ionomycin at concentrations up to $10 \mu \mathrm{M}$ was shown to reduce the level of nuclear $\beta$-catenin (12). In addition, ionomycin disrupted the binding of TCF complexes to their specific DNA response elements and subsequently the transcriptional activation of $\beta$-catenin target genes (12). In the present study, ionomycin was used to demonstrate whether $\beta$-catenin is involved in the proposed signalling in melanoma cells. As shown in Figure 5, $10 \mu \mathrm{M}$ ionomycin inhibited transcriptional up-regulation of TFRC. Thus, $\beta$-catenin was identified as a component of the proposed signalling pathway triggered by HA. When the ionomycin concentration was elevated to $50 \mu \mathrm{M}$ the opposite effect was observed. TFRC expression was considerably increased due to the high $\mathrm{Ca}^{2+}$ concentration released from intracellular stores by IM. It is commonly accepted that calcium is an important signalling factor leading to activation of different kinases, e.g. kinase activation by $\mathrm{Ca}^{2+} /$ calmodulin or $\mathrm{Ca}^{2+} /$ diacylglycerol (DAG). $\mathrm{Ca}^{2+} / \mathrm{DAG}$ can activate PKC and it was shown that $\mathrm{Ca}^{2+}$ induces a shift of this enzyme to the cell membrane and to the nucleus (29). PKC can either act in the cytoplasm and cause the nuclear effects indirectly by triggering signalling pathways directed towards the cell nucleus, or itself acts in the cell nucleus after translocation and activation in the nucleus (30). Therefore, elevated $\mathrm{Ca}^{2+}$ level as described here for melanoma cells might cause an increase in TFRC by transcriptional activation via $\mathrm{PKC}$ or by accelerating TFRC recycling (31). The finding described here for HACD44 signalling leading to up-regulation of TFRC emphasizes the importance of CD44 and its main ligand HA for the proliferative ability of melanoma cells besides $\mathrm{WNT} / \beta$-catenin signalling.

Since $c-M Y C$ may be a target gene in CD44 signalling triggered by its main ligand molecule HA, melanoma cells are able to use the CD44/HA signalling for their upregulation of TFRC and subsequent iron supply.

\section{Conflicts of Interest}

The Authors declare the absence of potential conflict of interests in regard to this study.

\section{References}

1 Kwok JC and Richardson DR: The iron metabolism of neoplastic cells: alterations that facilitate proliferation? Crit Rev Oncol Hematol 42: 65-78, 2002.

2 Rahmanto YS, Bal S, Loh KH, Yu Y and Richardson DR: Melanotransferrin: search for a function. Biochim Biophys Acta 1820: 237-243, 2012.

3 Michaud-Levesque J, Demeule M and Béliveau R: Stimulation of cell surface plasminogen activation by membrane-bound melanotransferrin: a key phenomenon for cell invasion. Exp Cell Res 308: 479-490, 2005.

4 Laube F: Co-localization of CD44 and urokinase-type plasminogen activator on the surface of human melanoma cells. Anticancer Res 20: 5045-5048, 2000.

5 Dunn LL, Sekyere EO, Suryo Rahmanto Y and Richardson DR: The function of melanotransferrin: a role in melanoma cell proliferation and tumorigenesis. Carcinogenesis 27: 2157-2169, 2006.

6 Paluncic J, Kovacevic Z, Jansson PJ, Kalinowski D, Merlot AM, Huang MLH, Lok HC, Sahni S, Lane DJR and Richardson DR: Roads to melanoma: key pathways and emerging players in melanoma progression and oncogenic signalling. Biochim Biophys Acta 1863: 770-784, 2016.

7 Richardson DR, Kalinowski DS, Lau S, Jansson PJ and Lovejoy DB: Cancer cell iron metabolism and the development of potent iron chelators as anti-tumor agents. Biochim Biophys Acta 1790: 702-717, 2009.

8 Bourguignon LYW, Peyrollier K, Gilad E and Brightman A: Hyaluronan-CD44 interaction with neural Wiskott-Aldrich syndrome protein (N-WASP) promotes actin-polymerization and ErbB2 activation leading to $\beta$-catenin nuclear translocation, transcriptional up-regulation, and cell migration in ovarian tumor cells. J Biol Chem 282: 1265-1280, 2007.

9 Yochum GS, Cleland R and Goodman RH: A genome-wide screen for $\beta$-catenin binding sites indentifies a downstream enhancer element that controls c-Myc gene expression. Mol Cel Biol 28: 7368-7379, 2008. 
10 Herbst A, Jurinovic V, Krebs S, Thieme SE, Blum H, Göke B and Kolligs FT: Comprehensive analysis of $\beta$-catenin target genes in colorectal carcinoma cell lines with deregulated $\mathrm{Wnt} / \beta$ catenin signalling. BMC Genomics 15: 1-15, 2014.

11 Zeller KI, Jegga AG, Aronow BJ, O'Donnell KA and Dang CV: An integrated database of genes responsive to the Myc oncogenic transcription factor: identification of direct genomic targets. Genome Biol 4: R69.1-R69.10, 2003.

12 Park CH, Hahm ER, Lee JH, Jung KC, Rhee HS and Yang CH: Ionomycin downregulates $\beta$-catenin/Tcf signalling in colon cancer cell line. Carcinogenesis 26: 1929-1933, 2005.

13 Chatila T, Silverman L, Miller R and Geha R: Mechanisms of T-cell activation by the calcium ionophore ionomycin. J Immunol 143: 1283-1289, 1989.

14 Aubert C, Rougé F and Galindo JR: Tumorigenicity of human malignant melanocytes in nude mice in relation to their differentiation in vitro. J Natl Cancer Inst 64: 1029-1040, 1980.

15 Kricka LJ and Thorpe GHG: Bioluminescent and chemiluminescent detection of horseradish peroxidase labels in ligand binder assays. In: Luminescence Immunoassay and Molecular Applications. Van Dyke K and Van Dyke R (eds.). Boca Raton, CRC Press, pp. 77-98, 1990.

16 Laube F: Mannose-6-phosphate/insulin-like growth factor-II receptor in human melanoma cells: effect of ligands and antibodies on the receptor expression. Anticancer Res 29: 13831388, 2009.

17 Ishibe M, Rosier RN and Puzas JE: Activation of osteoblast insulin-like growth factor-II/cation-independent mannose-6phosphate receptors by specific phosphorylated sugars and antibodies induce insulin-like growth factor-II effects. Endocrine Res 17: 357-366, 1991.

18 Feinmesser M, Veltman V, Morgenstern S, Tobar A, Gutman H, Kaganovsky E, Tzabari C, Sulkes J and Okon E: Different patterns of expression of the erbB family of receptor tyrosine kinases in common nevi, dysplastic nevi, and primary melanomas: an immunohistochemical study. Am J Dermatopathol 32: 665-675, 2010.

19 Tortorella S and Karagiannis TC: Transferrin receptor-mediated endocytosis: a useful target for cancer therapy. J Membrane Biol 247: 291-307, 2014.

20 Rolland Y, Demeule M, Michaud-Levesque J, and Béliveau R: Inhibition of tumor growth by a truncated and soluble form of melanotransferrin. Exp Cell Res 313: 2910-2919, 2007.

21 Rolland Y, Demeule M, Fenart L and Béliveau R: Inhibition of melanoma brain metastasis by targeting melanotransferrin at the cell surface. Pigment Cell Melanoma Res 22: 86-98, 2009.
22 Yang J, Tiong J, Kennard M and Jefferies WA: Deletion of the GPI pre-anchor sequence in human p97 - a general approach for generating the soluble form of GPI-linked proteins. Protein Expr Purif 34: 28-48, 2004.

23 Brown JP, Nishiyama K, Hellström I and Hellström KE: Structural characterization of human melanoma-associated antigen p97 with monoclonal antibodies. J Immunol 127: 539546, 1981.

24 Rahmanto YS, Dunn LL and Richardson DR: Identification of distinct changes in gene expression after modulation of melanoma tumor antigen $\mathrm{p} 97$ (melanotransferrin) in multiple models in vitro and in vivo. Carcinogenesis 28: 2172-2183, 2007.

25 Ahrens T, Assmann V, Fieber C, Termeer CC, Herrlich P, Hofmann M and Simon JC: CD44 is the principal mediator of hyaluronic-acid-induced melanoma cell proliferation. J Invest Dermatol 116: 93-101, 2001.

26 Röhrs S, Kutzner N, Vlad A, Grunwald T, Ziegler S and Müller O: Chronological expression of Wnt target genes Ccndl, Myc, Cdkn1a, Tfrc, Plf1 and Ramp3. Cell Biol Intern 33: 501-508, 2009.

27 Liu J, Fukunaga-Kalabis M, Li L and Herlyn M: Developmental pathways activated in melanocytes and melanoma. Arch Biochem Biophys 563: 13-21, 2014.

28 O’Donnell KA, Yu D, Zeller KI, Kim J, Racke F, ThomasTikhonenko A and Dang CV: Activation of transferrin receptor 1 by c-Myc enhances cellular proliferation and tumorigenesis. Mol Cell Biol 26: 2373-2386, 2006.

29 Maasch C, Wagner S, Lindschau C, Alexander G, Buchner K, Gollasch M, Luft FC and Haller H: Protein kinase Ca targeting is regulated by temporal and spatial changes in intracellular free calcium concentration $\left[\mathrm{Ca}^{2+}\right]_{\mathrm{i}}$. FASEB J 14: 1653-1663, 2000.

30 Buchner $\mathrm{K}$ : The role of protein kinase $\mathrm{C}$ in the regulation of cell growth and in signalling to the cell nucleus. J Cancer Res Clin Oncol 126: 1-11, 2000.

$31 \mathrm{Ci}$ W, Li W, Ke Y, Qian ZM and Shen X: Intracellular $\mathrm{Ca}^{2+}$ regulates the cellular iron uptake in K562 cells. Cell calcium 33: 257-266, 2003. 